\title{
ORIGEM E DISTRIBUIÇÃO ANTIMÉRICA DOS NERVOS FEMORAIS EM CAPRINOS RECÉM-NATOS DA RAÇA SAANEN
}

\section{ORIGIN AND ANTIMERIC DISTRIBUTION OF THE FEMORAL NERVES IN NEWBORNS GOATS OF THE SAANEN BREED}

\author{
Renata Medeiros-do-Nascimento ${ }^{1}$ \\ Thais Mattos Estruc ${ }^{1}$ \\ Jorge Luiz Alves-Pereira ${ }^{2}$ \\ Paulo Oldemar Scherer ${ }^{3}$ \\ Marcelo Abidu-Figueiredo ${ }^{3}$ \\ 1 Zootecnista Autônoma. \\ 2Discente do curso de Pós-Graduação em Biologia Humana e Experimental, Universidade do Estado do Rio \\ de Janeiro, RJ, Brasil. \\ ${ }^{3}$ Docente da Área de Anatomia, Departamento de Biologia Animal, Universidade Federal Rural do Rio de \\ Janeiro, Seropédica, RJ, Brasil - marceloabidu@gmail.com
}

\section{Resumo}

O nervo femoral foi estudado em 33 caprinos recém-natos da raça Saanen (22 machos e 11 fêmeas), que, após morte natural, foram fixados com solução de formaldeído a 10\%. Nos machos, o nervo femoral teve sua origem nos ramos espinhais ventrais de L4 e L5 em oito animais (36\%); em seis animais (27\%) teve sua origem nos ramos espinhais ventrais de L5 e L6; em cinco animais (23\%) teve sua origem no ramo espinhal ventral de L5; em dois animais (9\%) teve sua origem nos ramos espinhais ventrais de L4, L5 e L6; em um animal (5\%) teve sua origem dos ramos espinhais ventrais de L5 e L6 e no ramo espinhal ventral de S1. Nas fêmeas, teve sua origem nos ramos espinhais ventrais de L4 e L5 em sete animais (64\%); em três animais (27\%) teve sua origem nos ramos espinhais ventrais de L5 e L6 e em um animal (9\%) teve sua origem nos ramos espinhais ventrais de L4, L5 e L6. Os nervos femorais emitiram, em todos os animais, número variável de ramos para os músculos psoas maior, psoas menor, quadríceps femoral, sartório e pectíneo.

Palavras-chave: nervo femoral; Saanen; variação.

\begin{abstract}
The femoral nerves were studied in newborn goats of Saanen breed (22 males and 11 females) that were collected after natural death and fixed with $10 \%$ formaldehyde solution. In males the femoral nerve arose from the ventral spinal branches of L4 and L5 in eight animals (36\%); in six animals $(27 \%)$ it arose from the ventral spinal branches of L5 and L6; in five animals (23\%) it arose from the ventral spinal branches of L5; in two animals (9\%) it arose from the ventral spinal branches of L4, L5 and L6 and in one animal (5\%) it arose from the ventral spinal branches of L5 and L6 and the ventral spinal branches of $\mathrm{S} 1$. In females the femoral nerve arose from the ventral spinal branches of


L4 and L5 in seven animals (64\%); in three animals (27\%) it arose from the ventral spinal branches of L5 and L6 and in one animal (9\%) it arose from the ventral spinal branches of L4, L5 and L6. In all animals, the femoral nerves were distributed in different branches to the major and minor psoas, femoris quadriceps, sartorius and pectinius muscles.

Keywords: femoral nerve; Saanen; variation.

Recebido em: 05 julho 2013.

Aceito em: 14 janeiro 2015.

\section{Introdução}

Os critérios para a avaliação da dor em ruminantes têm recebido pouca atenção quando comparado aos animais de companhia, pois eles raramente mostram sinais clássicos de dor, tais como vocalização, agitação ou atividade motora violenta; sendo assim, pesquisas que descrevam as estruturas relacionadas à dor apresentam relevância e devem ser incentivadas ${ }^{(1)}$.

Devido às semelhanças anatômicas com o joelho humano, os pequenos ruminantes estão cada vez mais sendo utilizados como modelo experimental para pesquisa comparada em ortopedia ${ }^{(2)}$; com isso, torna- se essencial o conhecimento topográfico da inervação do membro pélvico. Dellmann e McClure $^{(3)}$ afirmam que, nos ruminantes, o nervo femoral é formado pelo ramo ventral do quinto nervo espinhal lombar (L5), com contribuições de modo variável, do quarto (L4) e do sexto nervos lombares (L6). Normalmente, deriva de fibras dos ramos ventrais de L5 e L6 no ovino, e de fibras de L5 com contribuição variável de L4 no caprino.

O nervo femoral é responsável pela inervação do musculo quadríceps da coxa, dos iliopsoas, ilíaco, sartório, psoas maior e pectíneo ${ }^{(4)}$. A lesão grave deste nervo, embora relativamente rara, determina sérias consequências como a paralisia do músculo quadríceps, impedindo a fixação da articulação do joelho e, dessa forma, todo o membro torna-se incapaz de suportar peso e tem-se a inibição do reflexo patelar, não sendo possível compensar esta deficiência. A lesão desse nervo também ocasiona a perda de sensibilidade na face medial do membro pélvico. Possíveis causas de paralisia femoral incluem as fraturas pélvicas ${ }^{(3,4)}$.

Radostits et al. ${ }^{(5)}$ relataram a paralisia do nervo femoral em bezerros, com histórico de distocia. A tração utilizada para o nascimento desses bezerros causa hiperextensão do fêmur e distensão do músculo quadríceps com seus suprimentos sanguíneo e nervoso. Na maioria dos casos, o nervo femoral direito é o acometido. Tais bezerros, alguns dias após o nascimento, apresentam o músculo quadríceps atrofiado no membro acometido, podendo facilmente ter a patela luxada.

O perfeito conhecimento da anatomia topográfica do nervo femoral permite seu acesso cirúrgico e bloqueio anestésico por diferentes vias. Em animais submetidos a procedimentos cirúrgicos dos membros pélvicos, o bloqueio do nervo femoral assim como de outros nervos que compõem o plexo lombosacral é satisfatório, podendo ser uma técnica alternativa à anestesia geral ${ }^{(6)}$.

O presente trabalho teve como objetivo caracterizar a origem e as principais ramificações musculares dos nervos femorais em ambos os antímeros e nos dois sexos, em caprinos recém-natos da raça Saanen, fornecendo, assim, subsídio anatômico para estudos comparados, bem como para a clínica médica e cirúrgica. 


\section{Material e Métodos}

Foram utilizados cadáveres de 33 caprinos da raça Saanen recém-natos, sendo 22 machos e 11 fêmeas, com aproximadamente um mês de idade, pertencentes ao acervo da Área de Anatomia Animal da Universidade Federal Rural do Rio de Janeiro. Esses cadáveres já se encontravam fixados e conservados em solução de formaldeído a $10 \%$. Inicialmente, os cadáveres foram lavados em água corrente, sexados e identificados por meio da colocação de etiqueta plástica numerada fixada com barbante ao tendão calcanear comum. Com o auxílio de uma trena metálica, foi mensurado o comprimento rostro-sacral de cada animal, tendo como referência a extremidade do focinho até a inserção da cauda.

Para o conhecimento das origens dos nervos femorais direito e esquerdo, promoveu-se uma incisão ao nível da linha mediana ventral, desde o processo xifóide do osso esterno, até a borda caudal da sínfise pélvica e, a partir desta, duas outras verticais foram efetuadas, uma em cada antímero, até se alcançar a linha mediana dorsal. Em seguida, promoveu-se a desarticulação da sínfise pélvica, por meio de secção longitudinal, atingindo-se, por conseguinte, a cavidade pélvica, da qual foram retirados todos os seus órgãos. Após remoção de parte do tecido adiposo e rebatimento dos músculos psoas, visualizaram-se os ramos ventrais dos nervos espinhais lombares e sacrais de ambos os antímeros. Essa exposição permitiu a identificação dos ramos ventrais que originam o nervo femoral. Para análise das distribuições dos ramos musculares dos nervos femorais que emergem ao longo de cada tronco nervoso em seu respectivo antímero, efetuou-se uma incisão circular na pele do terço médio da perna e outra vertical na pele da face medial da coxa, estendendo-a desde a raiz do membro pélvico até a primeira incisão na perna. Após dissecação, identificaram-se os ramos musculares dos nervos femorais em ambos os antímeros, sendo emitidos ao longo de seus trajetos. Foram elaborados desenhos esquemáticos e documentação fotográfica. Foram calculadas as frequências absoluta e percentual simples dos ramos que deram origem aos nervos femorais em ambos os sexos e antímeros, bem como a frequência de ramos dos nervos femorais que se destinaram aos músculos dos antímeros direito e esquerdo em ambos os sexos. Os dados para os ramos musculares dos nervos femorais foram apresentados como média \pm desvio padrão. O teste de Kolmorogov-Smirnov (K-S) foi utilizado para avaliar a normalidade das amostras de cada uma das variáveis. A análise estatística foi realizada através do teste de Mann-Whitney e o nível de significância considerado foi de $\mathrm{P}<0,05$.

Com o intuito de verificar se a distribuição de frequências observadas para os 33 animais examinados estava de acordo com a teoria, aplicou-se o teste do $\chi^{2}$ (Qui-quadrado), a $5 \%$ de significância, para testar se a hipótese de nulidade é verdadeira, isto é, se as origens dos nervos não dependem do sexo do animal nem do antímero. Para a avaliação dos dados estatísticos e confecção dos gráficos foi utilizado o software GraphPad Prism 6.

\section{Resultados e Discussão}

Nos machos, o nervo femoral teve sua origem simétrica nos ramos ventrais do quarto e quinto nervos espinhais lombares em oito animais (36\%) (Figura 1A); em seis animais (27\%) teve sua origem nos ramos ventrais do quinto e sexto nervos espinhais lombares; em cinco animais (23\%) teve sua origem 
no ramo ventral do quinto nervo espinhal lombar; em dois animais (9\%) teve sua origem nos ramos ventrais do quarto, quinto e sexto nervos espinhais lombares (Figura 1B); e em um animal (5\%) teve sua origem nos ramos ventrais do quinto e sexto nervos espinhais lombares e no ramo ventral do primeiro nervo espinhal sacral. Nas fêmeas, também de maneira simétrica, o nervo femoral teve sua origem nos ramos ventrais do quarto e quinto nervos espinhais lombares em sete animais (64\%); em três animais (27\%) teve sua origem nos ramos ventrais do quinto e sexto nervos espinhais lombares; em um animal (9\%) teve sua origem nos ramos ventrais do quarto, quinto e sexto nervos espinhais lombares. No total de 33 animais dissecados, o ramo ventral de L5 esteve presente em 100\% das amostras (22 machos - 66,7\% e 11 fêmeas - 33,3\%), seguido pelo ramo ventral de L4 em 54,5\% das amostras (10 machos - 30,3 \% e 8 fêmeas - 24,2 \%), o ramo ventral de L6 em 39,4\% das amostras (9 machos - 27,3\% e 4 fêmeas - 12,1\%) e o ramo ventral de S1 em 3\% (1 macho).

Não foram observadas diferenças significativas entre as frequências da origem do nervo femoral em relação ao sexo $(p=0,37)$ e aos antímeros uma vez que a formação dos nervos foi simétrica.

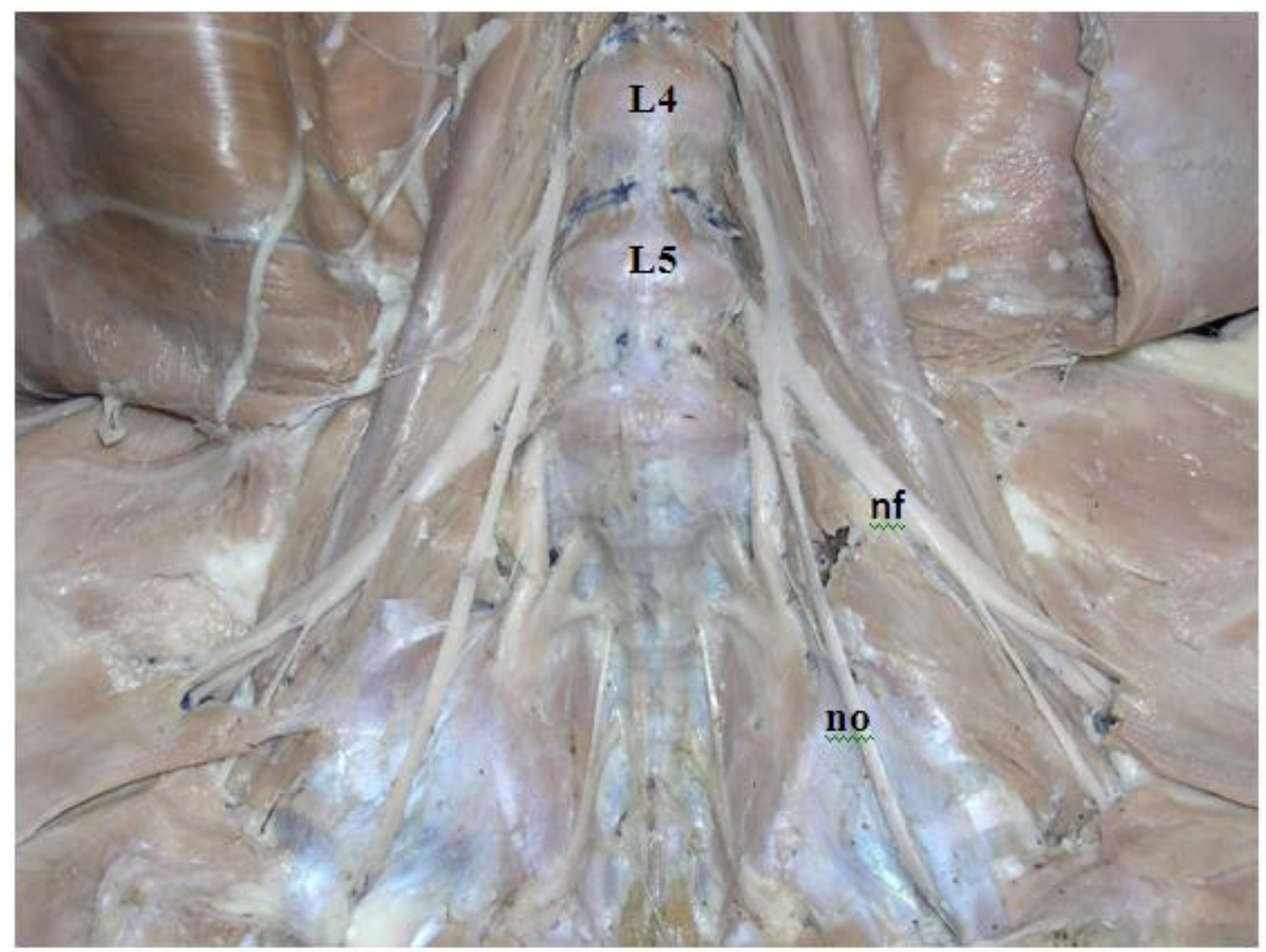

Figura 1A: Fotomicrografia da vista ventral da formação do nervo femoral em caprino, do sexo masculino, da raça Saanen: L4 = quarta vértebra lombar; L5 = quinta vértebra lombar; no $=$ nervo obturatório; $\mathrm{nf}=$ nervo femoral.

Os resultados referentes à distribuição dos ramos musculares dos nervos femorais em ambos os antímeros e nos dois sexos estão representados nas tabelas 1 e 2 e nas figuras $1 \mathrm{C}, 2 \mathrm{~A}, 2 \mathrm{~B}, 2 \mathrm{C}$ e 2D. 


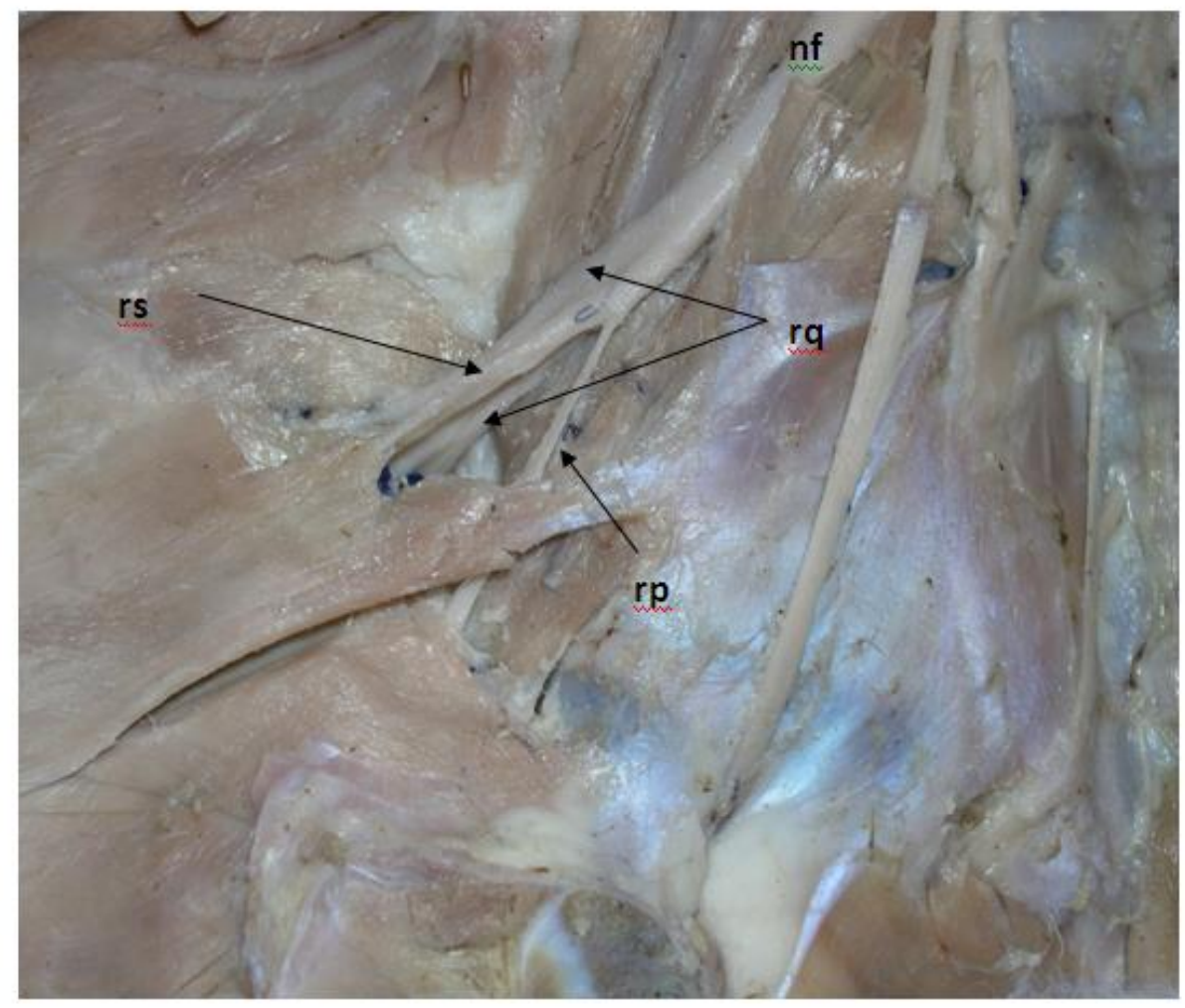

Figura 1B: Fotomicrografia da vista ventral do nervo femoral e seus ramos musculares em caprino, do sexo masculino, da raça Saanen: $\mathrm{nf}=$ nervo femoral; $\mathrm{rs}=$ ramo para o músculo sartório; $\mathrm{rq}=$ ramo para o músculo quadríceps; $\mathrm{rp}=$ ramo para o músculo pectíneo.

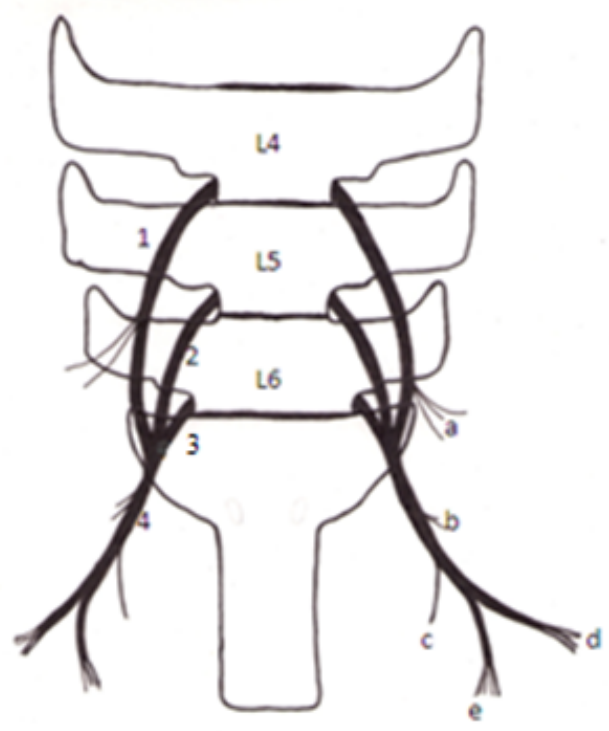

Figura 1C: Desenho esquemático mostrando a formação bilateral do nervo femoral e seus ramos musculares: $\mathrm{L} 4$ = quarta vértebra lombar; L5 = quinta vértebra lombar; L6 = sexta vértebra lombar; 1 = ramo ventral do quarto nervo espinhal lombar; 2 ramo ventral do quinto nervo espinhal lombar; 3 = ramo ventral do sexto nervo espinhal lombar; 4 = nervo femoral; a $=$ ramos para o músculo psoas maior; $\mathrm{b}=$ ramos para o músculo psoas menor; $\mathrm{c}=$ ramos para o músculo adutor; $\mathrm{d}=$ ramos para o músculo grácil; $\mathrm{e}=$ ramos para o músculo pectíneo. 
Tabela 1: Frequência absoluta (FA) e percentual simples (FP) dos ramos musculares do nervo femoral em ambos os antímeros em caprinos do sexo feminino $(\mathrm{n}=11)$

\begin{tabular}{|c|c|c|c|c|c|c|c|c|c|c|c|c|c|c|c|c|c|c|c|c|}
\hline \multirow{3}{*}{$\begin{array}{c}\text { Músculos } \\
\text { Antímeros } \\
\text { Ramos }\end{array}$} & \multicolumn{4}{|c|}{ Psoas maior } & \multicolumn{4}{|c|}{ Psoas menor } & \multicolumn{4}{|c|}{ Quadríceps } & \multicolumn{4}{|c|}{ Sartório } & \multicolumn{4}{|c|}{ Pectíneo } \\
\hline & \multicolumn{2}{|r|}{ D } & \multicolumn{2}{|r|}{$\mathbf{E}$} & \multicolumn{2}{|r|}{ D } & \multicolumn{2}{|r|}{$\mathbf{E}$} & \multicolumn{2}{|r|}{ D } & \multicolumn{2}{|r|}{$\mathbf{E}$} & \multicolumn{2}{|c|}{ D } & \multicolumn{2}{|c|}{$\mathbf{E}$} & \multicolumn{2}{|r|}{ D } & \multicolumn{2}{|r|}{$\mathbf{E}$} \\
\hline & FA & $\mathbf{F P}$ & FA & FP & $\mathbf{F A}$ & FP & FA & FP & FA & FP & FA & FP & FA & $\mathbf{F P}$ & FA & FP & FA & FP & FA & FP \\
\hline 1 & 5 & 45,45 & 4 & 36,36 & 4 & 36,36 & 4 & 36,36 & 1 & 9,09 & 1 & 9,09 & 11 & 100 & 10 & 90,90 & 9 & 81,82 & 7 & 63,64 \\
\hline 2 & 4 & 36,36 & 66 & 54,55 & 4 & 36,36 & 2 & 18,18 & 2 & 18,18 & 1 & 9,09 & 0 & 0 & 0 & 0 & 2 & 18,18 & 1 & 9,09 \\
\hline 3 & 1 & 9,09 & 0 & 0 & 1 & 9,09 & 3 & 27,27 & 3 & 27,27 & 4 & 36,36 & 0 & 0 & 0 & 0 & 0 & 0 & 0 & 0 \\
\hline 4 & 0 & 0 & 1 & 9,09 & 1 & 9,09 & 0 & 0 & 5 & 45,45 & 4 & 36,36 & 0 & 0 & 0 & 0 & 0 & 0 & 0 & 0 \\
\hline 5 & 1 & 9,09 & 0 & 0 & 0 & 0 & 0 & 0 & 0 & 0 & 0 & 0 & 0 & 0 & 0 & 0 & 0 & 0 & 0 & 0 \\
\hline 6 & 0 & 0 & 0 & 0 & 0 & 0 & 0 & 0 & 0 & 0 & 1 & 9,09 & 0 & 0 & 0 & 0 & 0 & 0 & 0 & 0 \\
\hline Ausente & 0 & 0 & 0 & 0 & 1 & 9,09 & 2 & 18,18 & 0 & 0 & 0 & 0 & 0 & 0 & 1 & 0,09 & 0 & 0 & 3 & 27,27 \\
\hline
\end{tabular}

Tabela 2: Frequência absoluta (FA) e percentual simples (FP) dos ramos musculares dos nervos femorais em ambos os antímeros em caprinos do sexo masculino $(\mathrm{n}=22)$

\begin{tabular}{|c|c|c|c|c|c|c|c|c|c|c|c|c|c|c|c|c|c|c|c|c|}
\hline \multirow{2}{*}{$\begin{array}{l}\text { Músculos } \\
\text { Antímeros }\end{array}$} & \multicolumn{4}{|c|}{ Psoas maior } & \multicolumn{4}{|c|}{ Psoas menor } & \multicolumn{4}{|c|}{ Quadríceps } & \multicolumn{4}{|c|}{ Sartório } & \multicolumn{4}{|c|}{ Pectíneo } \\
\hline & & D & & $\mathbf{E}$ & & D & & E & & D & & E & & D & & E & & D & & $\mathbf{E}$ \\
\hline Ramos & FA & FP & FA & FP & FA & FP & FA & FP & FA & FP & FA & FP & FA & FP & FA & FP & FA & FP & FA & FP \\
\hline 1 & 8 & 36,36 & 9 & 40,90 & 9 & 40,90 & 11 & 100 & 4 & 18,18 & 3 & 13,64 & 22 & 100 & 20 & 90,90 & 16 & 72,73 & 167 & 72,73 \\
\hline 2 & 4 & 18,18 & 6 & 27,27 & 8 & 36,36 & 3 & 13,64 & 6 & 27,27 & 3 & 13,64 & 0 & 0 & 0 & 0 & 3 & 13,64 & 1 & 4,55 \\
\hline 3 & 1 & 4,55 & 0 & 0 & 1 & 4,55 & 4 & 18,18 & 9 & 40,90 & 11 & 50 & 0 & 0 & 0 & 0 & 0 & 0 & 0 & 0 \\
\hline 4 & 0 & 0 & 0 & 0 & 0 & 0 & 0 & 0 & 2 & 9,09 & 4 & 18,18 & 0 & 0 & 0 & 0 & 0 & 0 & 0 & 0 \\
\hline 5 & 0 & 0 & 0 & 0 & 0 & 0 & 0 & 0 & 1 & 4,55 & 1 & 4,55 & 0 & 0 & 0 & 0 & 0 & 0 & 0 & 0 \\
\hline Ausente & 9 & 40,9 & 7 & 31,82 & 4 & 18,18 & 4 & 18,18 & 0 & 0 & 0 & 0 & 0 & 0 & 2 & 9,09 & 3 & 13,64 & 52 & 22,73 \\
\hline
\end{tabular}

De acordo com Dellmann e McClure ${ }^{(3)}$, o nervo femoral nos ruminantes é formado pelo ramo ventral de L5, podendo apresentar contribuições de L4 e de L6. Nos ovinos, suas fibras derivam normalmente dos ramos ventrais de L5 e L6 e, em caprinos, dos ramos ventrais de L5 com participação variável de L4, assemelhando-se em parte aos resultados obtidos na presente pesquisa.

Em pesquisa sobre a origem do nervo femoral em ovinos sem raça definida, Silva et al. ${ }^{(7)}$ observaram que os nervos femorais originaram-se dos ramos ventrais de L4 a L6 em ambos os antímeros; sendo que de L6 em 3,3\% dos espécimes no antímero esquerdo e 6,6\% no direito, de L4 e L5 em 23,3\% em ambos os antímeros e de L5 e L6 em 73,3\% no esquerdo e $70 \%$ no direito, semelhante ao observado na presente investigação no que se refere à origem dos ramos ventrais, porém diferentes em relação à frequência percentual. 

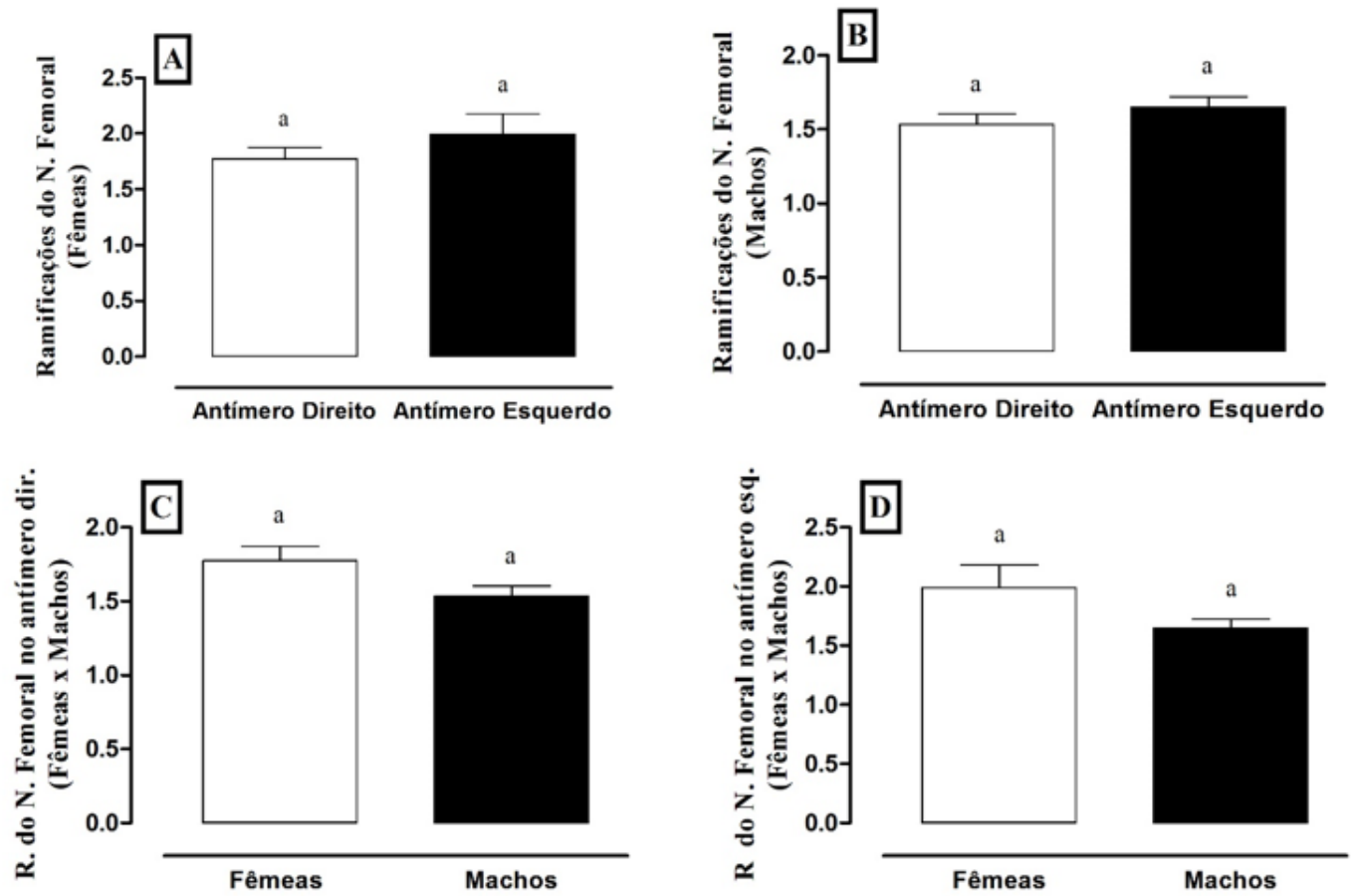

Figura 2: Valores da média e desvio-padrão da distribuição do número de ramos musculares do nervo femoral comparados entre sexos e antímeros: $\mathrm{A}=$ ramificações do nervo femoral em fềmeas nos dois antímeros; $\mathrm{B}=$ ramificações do nervo femoral em machos nos dois antímeros; $\mathrm{C}=$ ramificações do nervo femoral no antímero direito de fêmeas e machos; $\mathrm{D}=$ ramificações do nervo femoral no antímero esquerdo de fềmeas e machos.

Lizardo et al. ${ }^{(4)}$ estudaram a origem e a distribuição do nervo femoral em fetos de bovinos azebuados e verificaram que os nervos femorais direito e esquerdo originaramse a partir dos ramos ventrais de L4, L5 e L6 em 14 animais (46,7\%), a partir de L4 e L5 em 13 animais $(43,3 \%)$ e L5 e L6 em três animais (10\%), semelhante ao observado na presente pesquisa em caprinos e aos resultados obtidos por Silva et al. ${ }^{(7)}$ em ovinos sem raça definida no que se refere aos ramos ventrais, porém diferentes nas frequências percentuais. Ainda em seu estudo, Lizardo et al. ${ }^{(4)}$ encontraram simetria antimérica em todos os indivíduos analisados, diferentemente dos dados do presente trabalho com caprinos. O ramo ventral de L5 participou da formação do nervo femoral em todos os indivíduos avaliados, sendo variações a participação de L4, L6 e raramente de S1.

Mihelic et al. ${ }^{(8)}$ estudaram as formações e variações dos nervos femoral, obturatório e isquiático em carcaças de porcos com idade de 30 a 180 dias e, especificamente em relação ao nervo femoral, observaram que o referido nervo teve sua origem a partir dos ramos ventrais do quarto e quinto nervos espinhais lombares em quatro animais; do quarto, quinto e sexto nervos espinhais lombares em 157 animais; do terceiro, quarto e quinto nervos espinhais lombares em 36 animais; do quinto, sexto e sétimo nervos espinhais lombares em cinco animais; do terceiro, quarto, quinto e sexto nervos espinhais lombares em cinco animais; e a partir dos ramos ventrais do quarto, quinto, sexto e sétimo nervos espinhais lombares em cinco animais. No presente estudo, os nervos femorais em caprinos originaram-se dos ramos ventrais do quarto, quinto, sexto nervos espinhais e primeiro sacral; não foi 
observada emergência do nervo femoral a partir dos ramos ventrais do terceiro nervo espinhal lombar, fato este também confirmado por Silva et al. ${ }^{(7)}$ em ovinos sem raça definida.

Moraes et al. ${ }^{(9)}$ dissecaram 30 fetos de equinos, e observaram que os nervos femorais direito e esquerdo originaram-se a partir do terceiro, quarto, quinto e sexto ramos lombares ventrais, sendo que em $20(66,67 \%)$ fetos, este nervo originou-se do quarto e quinto ramos lombares ventrais, em sete $(23,33 \%)$ fetos do terceiro, quarto e quinto, em dois $(6,67 \%)$ fetos do terceiro e quarto e em um $(3,33 \%)$ feto do quarto, quinto e sexto ramos. Entretanto, no presente estudo em caprinos, não foi observada origem a partir de L3, fato este também confirmado por Silva et al. ${ }^{(7)} \mathrm{em}$ ovinos sem raça definida.

Dellmann e McClure ${ }^{(3)}$ afirmam que, em cães, o nervo femoral é formado pelo ramo ventral do quarto nervo espinhal lombar (L4), com contribuições variáveis do terceiro (L3) e do quinto nervos lombares (L5) e, ocasionalmente, do sexto nervo lombar (L6), assemelhando-se em parte aos resultados apresentados na presente investigação.

Gomes et al. ${ }^{(10)}$ estudaram a origem e a distribuição dos nervos femorais em 25 fetos de javalis (Sus scrofa) e verificaram que o referido nervo originou-se de L3 a S1, sendo a frequência predominante, em ambos os antimeros, L4, L5 e L6, semelhante aos resultados obtidos em porcos $^{(8)}$.

Aydin $^{(11)}$ observou que no porco-espinho (Hystrix cristata) os nervos femorais originaram-se principalmente dos ramos ventrais de L2 e L3, com contribuições de T15 e L1, diferente do observado na presente investigação.

Cardoso et al. ${ }^{(12)}$ estudaram a composição do plexo lombossacral do tamanduá-mirim (Tamandua tetradactyla) e observaram a contribuição dos ramos lombares (L1-L3) em todos os espécimes estudados, além da participação de T18 em 75\% deles na formação do nervo femoral. Essa formação assemelha-se à do porco-espinho $\left(\right.$ T15, L1-L3) ${ }^{(11)}$ e difere do observado em caprinos na presente pesquisa.

Oliveira et al. ${ }^{(13)}$ observaram que no preá (Galea spixii) o nervo femoral originou-se das raízes ventrais de L5 e L6, semelhante ao observado por Tonini et al. ${ }^{(14)}$ em pacas (Cuniculus paca) e em parte aos resultados encontrados na presente investigação.

Martinez-Pereira e Rickes ${ }^{(15)}$ observaram que na chinchila (Chinchila lanigera) o nervo femoral originou-se das raízes ventrais de L4 e L5, semelhante em parte aos resultados encontrados na presente investigação.

Castro et al. ${ }^{(16)}$ verificaram no lobo-marinho (Arctocephalus australis) que este nervo surge da união dos segmentos L3 e L4, arranjo semelhante ao observado por Mihelić et al. ${ }^{(17)}$ para o leão marinho da Califórnia (Zalophus californianus) e para o elefante marinho do norte (Mirounga augustirostris), diferente do encontrado na presente pesquisa.

Oliveira et al. ${ }^{(18)}$ observaram que a origem do nervo femoral no mocó (Kerodon rupestres), em geral, variou entre o quarto, quinto, sexto e sétimo nervos espinhais lombares, apresentando-se simetricamente na sua origem entre os antímeros direito e esquerdo em $80 \%$ e assimétricos em $20 \%$ dos exemplares, assemelhando-se, em parte, aos resultados obtidos na presente pesquisa.

Em um estudo sobre a morfologia do plexo lombossacral da jaguatirica (Leopardus pardalis), Lopes et al. ${ }^{(19)}$ observaram que, em L4, houve a formação do nervo femoral, assemelhando-se em parte aos resultados obtidos na presente pesquisa.

Souza et al. ${ }^{(20)}$ estudaram a ramificações dos nervos femorais no tamanduá-bandeira (Myrmecophaga tridactyla) e observaram que as origens dos nervos femorais nos antímeros direito e esquerdo ocorreram dos ramos ventrais dos nervos espinhais lombares L1, L2 e L3. Entretanto, Cruz et al. ${ }^{\text {(21) }}$ 
também observaram a participação de segmentos torácicos (T15, T16) na formação do nervo femoral no tamanduá-bandeira (Myrmecophaga tridactyla). Esse arranjo assemelha-se ao do porcoespinho $^{(11)}$, e do tamanduá-mirim ${ }^{(12)}$, mas difere do observado em caprinos no presente estudo.

Nesta investigação, em todos os espécimes, os nervos femorais direito e esquerdo emitiram número variado de ramos para os músculos psoas maior e menor, sartório, pectíneo e quadríceps femoral. Resultados semelhantes foram obtidos por Silva et al. ${ }^{(7)} \mathrm{em}$ ovinos sem raça definida; contudo esses autores observaram ramos musculares para o músculo ilíaco medial, não observado na presente pesquisa.

Em pesquisa realizada com fetos de bovinos azebuados, Lizardo et al. ${ }^{(4)}$ observaram que, em relação à distribuição, o nervo femoral difundiu-se através do músculo psoas maior (100\%), ilíaco (100\%), pectíneo (56,7\%), quadríceps femoral (100\%) e emitiu o nervo safeno, que deu ramos para o músculo pectíneo $(43,3 \%)$ e sartório (100\%) e continuou distalmente ao longo da artéria e veia safena para se dividir na pele da face medial do joelho e na perna em ambos os antímeros, diferente dos resultados no presente estudo em que não foram observados ramos para o músculo ilíaco além de diferentes frequências.

$\mathrm{Na}$ presente investigação, os nervos femorais em caprinos recém-natos da raça Saanen emitiram número variado de ramos para os músculos psoas maior e menor, sartório, pectíneo e quadríceps femoral. Não foram observadas diferenças significativas no número total de ramos musculares dos nervos femorais em relação aos antímeros $(\mathrm{p}=0,78)$, no número de ramos musculares para o antímero direito comparando-se os sexos $(\mathrm{p}=0,30)$ nem no número de ramos musculares para o antímero esquerdo em relação a sexo $(\mathrm{p}=0,51)$.

Moraes et al. ${ }^{(9)}$, em pesquisa realizada com fetos equinos, verificaram que em $100 \%$ dos fetos dissecados o nervo femoral distribuiu-se nos músculos vastos lateral, medial, intermédio e reto femoral, em $10(33,33 \%)$ no grácil, em oito $(26,66 \%)$ no psoa menor e em dois $(6,66 \%)$ na pele, discordando dos resultados obtidos neste estudo em que os nervos femorais direito e esquerdo emitiram ramos variados para os músculos psoas maior e menor, sartório, pectíneo e quadríceps femoral.

Gomes et al. ${ }^{(10)}$ observaram que os nervos femorais em fetos de javalis (Sus scrofa scrofa) emitiram número variável de ramos para os músculos ilíacos, psoas maior, sartório e quadríceps femoral em ambos os antímeros, semelhante em parte ao observado na presente pesquisa.

No mocó (Kerodon rupestres), Oliveira et al. ${ }^{(18)}$ verificaram que os nervos femorais emitiram número variável de ramos para os músculos ilíaco e quadríceps femoral, sartório e pectíneo, assemelhandose em parte aos resultados obtidos na presente investigação, em que também foram observados ramos para os músculos psoas maior e menor.

Na chinchila (Chinchila lanigera), Martinez-Pereira e Rickes ${ }^{(15)}$ observaram que os nervos femorais emitiram número variável de ramos para os músculos psoas maior e menor, quadríceps femoral, grácil, pectíneo e sartório, assemelhando em parte aos resultados obtidos na presente investigação e aos obtidos por Lopes et al. ${ }^{(19)} \mathrm{em}$ um estudo sobre a morfologia do plexo lombossacral da jaguatirica (Leopardus pardalis).

Castro et al. ${ }^{(16)}$ verificaram no lobo-marinho (Arctocephalus australis) que estes nervos emitiram número variável de ramos para os músculos psoas maior e menor, reto femoral, vasto externo e profundo, grácil e sartório, corroborando em parte os resultados obtidos na presente investigação.

No tamanduá-bandeira (Myrmecophaga tridactyla), Souza et al. ${ }^{(20)}$ observaram que os nervos femorais distribuíram-se para os músculos psoas maior e menor, ilíacos lateral e medial, pectíneo, Cienc. anim. bras. v.16,n.2, p. 251-261 abr./jun. 2015 
adutor magno, sartório e quadríceps femoral, semelhante em parte aos resultados obtidos por Oliveira et al. ${ }^{(18)}$ no mocó (Kerodon rupestres) e aos caprinos da presente pesquisa.

\section{Conclusão}

Os nervos femorais emitiram, em todos os animais, número variável de ramos para os músculos psoas maior, psoas menor, quadríceps femoral, sartório e pectíneo. Não foram observadas diferenças significativas entre as frequências da origem e nos ramos musculares dos nervos femorais em relação ao sexo e aos antímeros. O conhecimento topográfico do nervo femoral fornece informações importantes para a prática clínica e cirúrgica de animais de produção.

\section{Agradecimentos}

Os autores agradecem o apoio financeiro da FAPERJ e do CNPq.

\section{Referências}

1. Valverde A, Gunkel CI. Pain management in horses and farm animals. Journal of Veterinary Emergency and Critical care. 2005;15(4):295-307.

2. Dowd G, Gaynor JS, Alvis M. A comparison of transdermal fentanyl and oral phenylbutazone for postoperative analgesia in sheep. Veterinary Surgery. 1998;26(3):168.

3. Dellmann HD, Mcclure RC. Sistema Nervoso do Ruminante. In: Getty R, editor. Anatomia dos Animais Domésticos. 1. 5 ed ed. Rio de Janeiro: Guanabara Koogan; 1986. p. 998-1105.

4. Lizardo FB, Silva FOC, Severino RS, Guimarães EC, Santos LA, Eulálio FHF, et al. Origin and distribution of the femoral nerve in fetuses of zebu-crossed bovines. Brazilian Journal Morphological Science. 2009;26(2):91-6.

5. Radostits OM, Gay CC, Blood DC, Hinchicliff KW. Clínica Veterinária: um tratado de doenças dos bovinos, ovinos, suínos, caprinos e eqüinos. 9 ed. Rio de Janeiro: Guanabara Koogan; 2000.

6. Silva FOC, Pereira CCH, Bombonato PP. Anestesia do Membro Pelvino de Ovinos: Estudo Experimental. Revista da Faculdade de Zootecnia, Veterinaria e Agronomia. 1994;1(1):5-10.

7. Silva FOC, Brito TR, Vasconcelos BG, Canabrava HAN, Pereira CCH, Nolasco RM, et al. Origens e distribuições dos nervos femorais em ovinos sem raça definida. Bioscience Journal. 2011;27(6):978-81.

8. Mihelić D, Gjurčević-Kantura V, Markovinović S, Damjanović A, Trbojević-Vukičević T. Variations of formation of $\mathrm{n}$. femoralis, $\mathrm{n}$. obturatorius and n. ischiadicus in pigs. Veterinary Archives. 2004;74(4):261-70.

9. Moraes DV, Martins JD, Silva FOC, Drummond SS, Severino RS. Origem e distribuição do nervo femoral em equinos sem raça definida. Horizonte Científico. 2008;1(9):1-10.

10. Gomes ARA, Carneiro E Silva FO, Iglesias LP, Ribeiro LA, Souza TAM, Furlan NL. Origens e ramificações do nervo femoral em javalis (Sus scrofa scrofa linnaeus, 1758). Bioscience Journal. 2013;29(3):727-31. 
11. Aydin A. The dissemination of the pelvic limb nerves originating from the lumbosacral plexus in the porcupine (Hystrix cristata). Veterinarni Medicina. 2009;54(7):333-9.

12. Cardoso JR, Souza PR, Cruz VS, Benetti EJ, Brito E Silva MS, Moreira PC, et al. Estudo anatômico do plexo lombossacral de Tamandua tetradactyla. Arquivo Brasileiro de Medicina Veterinária e Zootecnia. 2013;65(6):1720-8.

13. Oliveira GB, Albuquerque JFG, Oliveira MF, Rodrigues MN, Sousa RS, Sousa ES, et al. Source and distribution of the lumbosacral plexus in spix's yellow-toothed cavy (Galea spixii spixii). Brazilian Journal Morphological Science. 2008;25(1-4):1-34.

14. Tonini MGO, Sasahara THC, Leal LM, Machado MRF. Origem e distribuição do plexo lombossacral da paca (Cuniculus paca, Linnaeus 1766). . Biotemas. 2014;27(2):157-62.

15. Martinez-Pereira MA, Rickes EM. The spinal nerves that constitute the lumbosacral plexus and their distribution in the chinchilla. South African Veterinarian Association. 2011;82(3):150-4.

16. Castro TF, Souza DAS, Silva Filho RP, Pereira MAM. Sistematização e distribuição da inervação lombar e sacral em Arctocephalus australis. Journal of Veterinary Research and Animal Science. 2009;46(5):404-11.

17. Mihelić D, Smodlaka H, Tkalčić S, Palmer L, Mršić G, Špiranec K, et al. Creation Nerves of the Lumbar and Sacral Plexus in California Sea Lions (Zalophus Californianus) and Northern Elephant Seals (Mirounga Angustirostris) Acta Veterinaria-Beograd 2014;64(3):293-306.

18. Oliveira GB, Albuquerque JFG, Rodrigues MN, Paiva ALC, Moura CEB, Miglino MA, et al. Origem e distribuição do nervo femoral do mocó, Kerodon rupestris (Cavidae). Pesquisa Veterinária Brasileira. 2011;31(1):84-8.

19. Lopes JA, Fe LCM, Lima ARD, Pereira LC, Branco E. Morfologia do plexo lombossacral da jaguatirica (Leopardus pardalis). Biotemas. 2012;25(4):215-20.

20. Souza TAM, Silva FOCE, Ribeiro LA, Ribeiro PRQ, Rosa LA, Santos ALQ, et al. Origens, distribuições e ramificações dos nervos femorais no tamanduá-bandeira (Myrmecophaga tridactyla Linnaeus, 1758). Biotemas. 2013;26(4):161-6.

21. Cruz VS, Cardoso JR, Araujo LBM, Souza PR, Borges NC, Araújo EG. Aspectos Anatômicos do Plexo Lombossacral de Myrmecophaga tridactyla (Linnaeus, 1758). Bioscience Journal 2014;30(1):235-44. 